\title{
SALUD
}

\section{Vivencias de mujeres consumidoras de pasta base de cocaína (PBC) del Barrio Ricardo Brugada de Asunción en el año 2015}

\author{
Sonia Mabel Recalde Benítez', Gloria Rumilda Ramírez Olmedo
}

\begin{abstract}
Resumen
Introducción: En Paraguay, según la Dirección General de Encuestas, Estadísticas y Censos en su Encuesta Permanente a Hogares (EPH, 2013), 23,8\% de la población es pobre relativo y extremo. Las mujeres, los niños, niñas y los adultos mayores son más susceptibles de padecer la pobreza. En relación a las mujeres consumidoras de drogas, en general, son estigmatizadas y discriminadas, acentuadas en los casos de usuarias problemáticas. El consumo de Pasta Base de Cocaína (en adelante PBC), prosaicamente llamado crack o chespi, es relativamente nuevo en el país, ha ido en aumento hasta llegar a ser inclusive la droga de inicio de niños y niñas desde el año 2005; la PBC es altamente adictiva, capaz de ocasionar estragos en el seno familiar y comunitario. En estudios recientes, se constató que en los centros de tratamiento 1 de 10 personas que buscaron asistencia son mujeres, además, demostró que, del total de las mujeres, el $43 \%$ buscó tratamiento por consumo de PBC.
\end{abstract}

Objetivo: Conocer las vivencias de las mujeres consumidoras de Pasta Base de Cocaína (PBC) del Barrio Ricardo Brugada de Asunción en el año 2015.

Material y Método: Es un estudio de nivel descriptivo, la metodología es cualitativa, la técnica utilizada es la entrevista semi-estructurada con el fin de obtener la óptica de las mujeres consumidoras de PBC. El instrumento consta de preguntas guías, la recolección de datos es construida a partir de la matriz metodológica. La muestra es de ocho mujeres que habitan en el Barrio Ricardo Brugada. Las consideraciones éticas tenidas en cuenta fueron el mantenimiento de la confidencialidad y la intimidad, consentimiento informado, protección contra daños fueron primordiales para salvaguardar la dignidad de las entrevistadas. El procedimiento para la selección de la muestra fue obtenida a través del visto bueno de las mujeres consumidoras de PBC, las entrevistas fueron desarrolladas en las viviendas precarias donde habitan, sector denominado Pelopincho. La situación socioeconómica, los recuerdos significativos de la niñez, el relacionamiento familiar, la esfera sexual, las

1. Instituto de Trabajo Social, Universidad Nacional de Asunción, Paraguay.

Tesis de grado presentado en el Instituto de Trabajo Social de la Universidad Nacional de Asunción en noviembre de 2015 para acceder a la Licenciatura en Trabajo Social.

Presentación de Póster en las XXV Jornadas de Jóvenes Investigadores organizada por Asociación de Universidades del Grupo Montevideo (AUGM) en octubre de 2017, Encarnación-Paraguay.

E-mail: somare.86@gmail.com

DOI: 10.26885/rcei.foro.2017.170 


\section{Vivencias de mujeres consumidoras de pasta base de cocaína. Recalde y Ramírez}

características del consumo de la PBC y la proyección al futuro de las mismas son las dimensiones abordadas.

Resultados: Entre los principales hallazgos se encuentran que las actividades económicas de las mujeres son ocasionales en contextos precarios como el reciclado, limpiaparabrisas, además, acciones que se encuentra en el límite de la del delito como es la elaboración de pipas caseras para la venta como mecanismo de reproducción del consumo de PBC. Por otro lado, la educación formal es escasa entre estas mujeres, solo una terminó el segundo año de la educación media y es la única que ejerce de peluquera, el trabajo más aceptado socialmente que le permite costear su consumo. Con respecto a las frustraciones durante la niñez, se encontró que las mujeres han sufrido varios tipos de violencia dentro de la esfera familiar, desde el abuso físico hasta el abandono por parte de los progenitores, todos los casos quedaron impunes. Actualmente el relacionamiento familiar es deficitario, hay una reconfiguración de roles donde la mujer consumidora de PBC recibe cuidados de sus hijos y anteriormente, ésta cuidaba de sus hermanos u otros familiares, ninguna de las mujeres vive con sus hijos, tanto familiares y los organismos de justicia las consideran incompetentes. En cuanto a la esfera sexual, está marcada por la violencia en las relaciones de pareja, esto ocasiona desinterés por encaminar nuevas relaciones, no mencionan disfrute de la sexualidad plena. En cuanto al consumo de la PBC está caracterizado por el policonsumo desde edades muy tempranas desde el tabaco, bebidas alcohólicas y drogas ilegales para intensificar el placer. Los motivos de consumo de PBC son diversos y complejos relacionadas con la violencia y el acceso a la justicia exigua, el consumo de PBC es un escape a la realidad cotidiana.

Conclusiones: El Estado debe asumir la responsabilidad pública y política para que las personas disfruten de la vida en dignidad; apostar por políticas públicas compensatorias integrales en los sectores excluidos, primordialmente poner énfasis en niñas y mujeres que son un sector profundamente afectado por la pobreza y la vulnerabilidad. En este sentido, cabe mencionar que la pobreza es violenta en sí misma porque socaban los derechos básicos como la educación, la salud, el acceso a la justicia, la vivienda, etc. Entre las recomendaciones se pueden mencionar que el Estado debe garantizar el cumplimiento efectivo de los derechos humanos a través de diferentes mecanismos eficientes y eficaces con la observación de la sociedad civil para lograr una sociedad que disfrute de una vida en plenitud.

Palabras clave: consumo de cocaína, mujeres, substancias psicoactivas.

\section{RefERENCIAS}

Oficina de las Naciones Unidas contra la Droga y el Delito. Programa Nacional Integrado para el Paraguay 2011-2014. (2013). Segundo Estudio Nacional sobre Personas con problemas derivados del consumo de alcohol y otras 
Rev. cient. estud. investing. VI Foro de Investigadores; diciembre 2017

drogas en centros de tratamiento y grupos de autoayuda. Autor.

Organización de los Estados Americanos. (2012). Escenarios para el problema de drogas en las Américas 2013 - 2025. Recuperado de http://www.oas.org/ documents/spa/press/Informe_de_Escenarios.pdf

Castaño, G.A. (2000). Cocaínas fumables en Latinoamérica. Revista Adicciones, 12 (4). 